\title{
Energy efficiency of DH system with wood chips boiler houses and flue gas condensing unit
}

\author{
Ģirts Vīgants, Gundars Galindoms, Ivars Veidenbergs, Dagnija Blumberga \\ Institute of Energy Systems and Environment \\ Riga Technical University \\ Riga, Latvia
}

girts.vigants@rtu.lv, gundars.galindoms@rtu.lv, ivars.veidenbergs@rtu.lv, dagnija.blumberga@rtu.lv

Received: December 10, 2019. Revised: October 13, 2021. Accepted: October 31, 2021. Published: November 14, 2021.

\begin{abstract}
This study proposes a method for the evaluation of the efficiency of a heat supply system based on a correlation analysis of the data of the system's operations. The data from the system's operations have been analysed and a correlation equation has been applied to obtain the results of the analysis, which are then used for further calculations. The data can be divided into two groups: data characterising the condenser operations in the boiler house, and data characterising heating networks.
\end{abstract}

Keywords - gas condenser; energy efficiency improvement; chips fuelled boiler house; heat supply system; heating network; climate technology

\section{INTRODUCTION}

The Latvian climate conditions impose particular requirements on the heat energy supply. This especially concerns district heating systems (DHS) - the dominant solution of supplying large cities with heat ( $~ 80 \%$ of the total number of heat energy users). Large DHS accounts for $70 \%$ of urban building heating in China. In North China, this proportion is even higher [1]. This is economically cost effective from many points of view, as it is possible to achieve a higher efficiency of the energy production [2]. Another advantage of compact DHS is the possibility to use the wholesale trade principle, since all the expenses forming the tariff per MWh produced in a large system are comparatively lower. At the same time, socio-economic and ecological reasons should also be taken into consideration, since they could be associated with a rise in employment and reduction in import, as well as with the possibility to mitigate environmental pollution and the greenhouse gas (GHG) emission effect $[3,4]$.

Currently, the Latvian energy sector faces a serious choice in its progress: to encourage all municipalities and local authorities to set based on the bottom-up method, short- and long-term goals of DHS development.

The short-term goal is: to secure - already now - as cheap heat supply as possible. In fact, this would force to choose cheap and inefficient equipment, and, which occurs quite often, to make an unjustified decision as to the liquidation of a DHS.
The long-term goal is: to realize in the future a stable and as low price as possible for heat energy that would be independent of the supply policy pursued by the supplier of imported fuel but dependent on the effectiveness of DHS operation. This would mean that the dominating current governmental policy has changed in the direction of sustainable heat supply. Efficient heat supply systems based on renewable energy sources are an important element of future energy systems that do not depend on fossil fuels. There is also important ecological aspect, because obtaining and using of energy generally has mostly negative environment impact [10]. End-use energy savings and the expansion of district heating are often mentioned as measures to make the heat supply sector in Denmark more sustainable [5]. Short and long-term plans have been made to fully utilize the renewable energy in municipal constructions, especially in Denmark, where a city using $100 \%$ renewable energy is proposed $[6,7]$.

The technology choice is that which, currently and in the future will be that which will dictate energy sector development in the area of heat supply to public and apartment houses. The installation and operation of an economical, cost effective boiler-house unit is associated with the necessity to reduce its operational cost in order to raise the efficiency of its functioning. For example, the installation of equipment for deep cooling at a boiler-house requires capital investments that could be paid back in 3-10 years, depending on the installed capacity and chosen type of equipment.

The operation of a chip-fuelled boiler house with installed gas condenser depends on the functioning of the heat-supply system as a whole. For example, the operation of the above mentioned boiler house depends on the energy efficiency of DHS users as well as on the water velocities and flows in all the elements of a heat network, including heat exchangers at the heat substations of the buildings [8]. To raise the amount of heat derived from a gas condenser, it is necessary to reduce the DHS returned water temperature [9]. This could be done by the qualitative and quantitative regulation of the DHS operating conditions and control over its functioning.

\section{METHODOLOGY FOR ENERGY EFFICIENCY EVALUATION}

This system evaluation model is intended for situations in which a flue gas condenser has been installed in the boiler 
house of a heat supply system, which helps to increase the total energy efficiency of the system.

Experience has shown that a flue gas condenser increases the efficiency of wood chip use by $10-20 \%$. The efficiency of such a system is influenced by various parameters of the operations of the heat supply system. In order to determine these parameters, an energy efficiency evaluation model consisting of eight blocks has been developed. The algorithm of the model is shown in Fig.1.

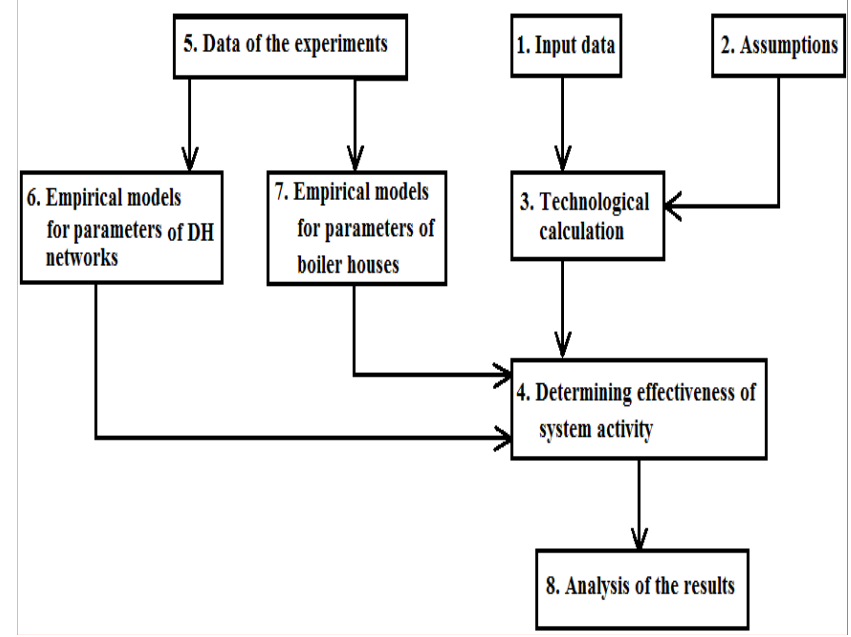

Fig.1. Algorithm for the model of evaluating the system

The parameters of the operation of a centralised heat supply system are influenced by both internal and external factors. In general, the system's efficiency is determined by multiplying the heat source efficiency by the heating network efficiency:

$$
\eta_{\text {sis }}=\eta_{\mathrm{bh}} * \eta_{\text {net }},
$$

where

$\eta_{\text {sis }}$ - total heat supply system efficiency;

$\eta_{\text {bh }}$ - boiler house efficiency;

$\eta_{\text {net }}-$ heating network efficiency.

Boiler house efficiency is determined with the help of a direct balance:

$$
\eta_{\mathrm{bh}}=\mathrm{Q}_{\mathrm{bh}} / \mathrm{B} * \mathrm{Q}_{\mathrm{h}}^{\mathrm{d}}
$$

where

$\mathrm{Q}_{\mathrm{bh}}$ - thermal energy produced in boiler house, $\mathrm{MWh} /$ year;

$\mathrm{B}$ - fuel consumption, $\mathrm{t} /$ year;

$\mathrm{Q}_{\mathrm{h}}{ }^{\mathrm{d}}-$ net heat value, $\mathrm{MWh} / \mathrm{t}$.

The efficiency of the heating network is determined with the following equation:

$$
\eta_{\text {net }}=1-Q_{\mathrm{hl}} / \mathrm{Q}_{\mathrm{bh}}
$$

where

$\mathrm{Q}_{\mathrm{hl}}$ - heat loss in heating networks, MWh/year.

In the further analysis instead of the energy the capacity of the units is used. The installation of an additional system in the boiler house, namely, a fuel condenser, provides for a part of the boiler house capacity. In such a case, boiler house capacity can be expressed as:

$$
\mathrm{N}_{\text {cap }}+\mathrm{K}_{\mathrm{ef}} \cdot \mathrm{N}_{\text {cap }}=\mathrm{N}_{\text {cap }} \cdot\left(1+\mathrm{K}_{\mathrm{ef}}\right), \quad \mathrm{MW},
$$

where

$\mathrm{N}_{\text {cap }}$ - boiler capacity, MW;

$\mathrm{K}_{\mathrm{ef}}$ - condenser efficiency.

Condenser efficiency is the relation of condenser capacity to boiler capacity $\mathrm{N}_{\text {con }} / \mathrm{N}_{\text {cap }}$, and this can be expressed as either a percentage or a fraction. Boiler house efficiency is then determined by the expression:

$$
\mathrm{H}_{\mathrm{bh}}=\left(\mathrm{N}_{\text {cap }} \cdot\left(1+\mathrm{K}_{\mathrm{ef}}\right)\right) / \mathrm{Q}_{\text {fuel }}
$$

where

$\mathrm{Q}_{\text {fuel }}$ - capacity introduced with fuel, MW.

The installation of a condenser increases the boiler house capacity or, in the case of a specific load, decreases the necessary capacity of the boiler.

The correlation $\mathrm{N}_{\text {cap }} / \mathrm{Q}_{\text {fuel }}$ is the efficiency of a boiler without a condenser. In such a case, the boiler house efficiency is determined as:

$$
H_{\text {bh }}=\eta_{\text {cap. }}\left(1+K_{e f}\right) .
$$

Using correlation (3), the heating system efficiency can be calculated with the following equation:

$$
\mathrm{H}_{\text {net }}=1-\mathrm{Q}_{\mathrm{hl}} /\left(\mathrm{N}_{\text {cap }} \cdot\left(1+\mathrm{K}_{\mathrm{ef}}\right)\right)
$$

Then the expression for the efficiency of a system that includes a boiler house and heating networks is determined thus:

$$
\begin{gathered}
\eta_{\text {sis }}=\left(\left(\mathrm{N}_{\text {cap }} \cdot\left(1+\mathrm{K}_{\mathrm{ef}}\right)\right) / \mathrm{Q}_{\text {fuel }}\right)\left(1-\mathrm{Q}_{\mathrm{hl}} /\left(\mathrm{N}_{\text {cap }} \cdot\left(1+\mathrm{K}_{\mathrm{ef}}\right)\right)\right)=\mathrm{N}_{\text {cap }} \cdot((1 \\
\left.\left.+\mathrm{K}_{\mathrm{ef}}\right)-\mathrm{Q}_{\mathrm{hl}} / \mathrm{N}_{\text {cap }}\right) / \mathrm{Q}_{\text {fuel }},
\end{gathered}
$$

or by inserting the expression for boiler efficiency:

$$
\eta_{\text {sis }}=\eta_{\text {cap. }}\left(\left(1+K_{\text {ef }}\right)-Q_{\text {hl }} / \mathrm{N}_{\text {cap }}\right)
$$

If we assume that the efficiency of a boiler without a condenser is a constant quantity, then the variable parameters, for example, depending on the outdoor temperature, are $\mathrm{K}_{\mathrm{ef}}$, $\mathrm{Q}_{\mathrm{hl}}$, and $\mathrm{N}_{\text {cap }}$. Empirical equations are obtained with the help of a correlation analysis in order to evaluate such changes.

\section{RESULTS OF THE EXPERIMENTS}

The flue gas condenser set up in the boiler house of the Ludza heating system has been operating for two years. The condenser has increased the total energy efficiency of the 
whole heating system. It is important to reach the maximum efficiency the system can provide and sustain this for the longest period possible.

A correlation analysis has been used to process the experimental data from the heating system. This analysis studies the interaction between several chance quantities and determines the closeness of the correlation between these quantities. The correlation coefficient determines how precise are the empirical equations characterising the closeness of the correlation. The squared values of the correlation coefficient are shown in the respective figures.

Changes in the efficiency of the condenser depending on outdoor temperature can be seen in Fig. 2.

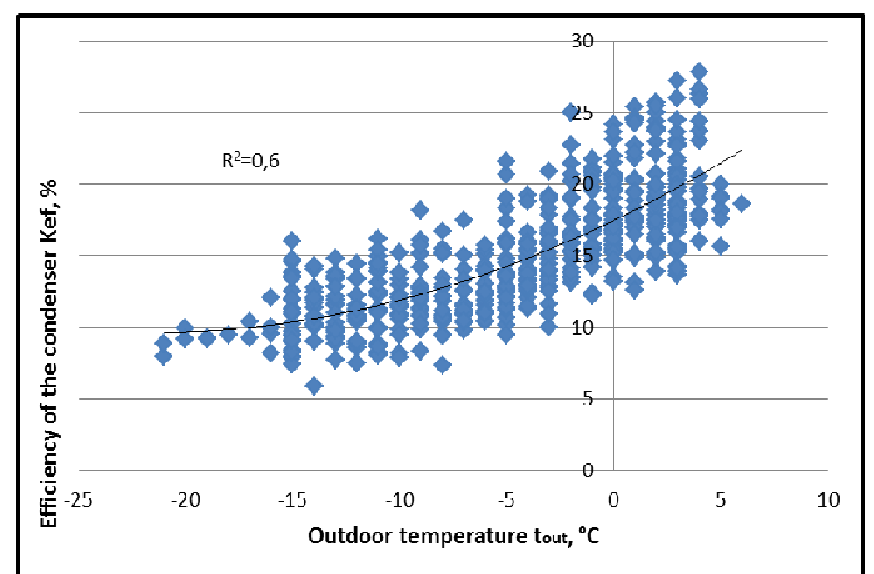

Fig. 2. Changes in condenser efficiency depending on outdoor temperature.

The changes are characterised by the following equation:

$$
\mathrm{K}_{\mathrm{ef}}=0.016 . \mathrm{t}_{\mathrm{out}}^{2}+0.721 . \mathrm{t}_{\mathrm{out}}+17.45
$$

When the outdoor temperature increases, the temperature of the return water decreases and deeper cooling of the flue gases takes place in the condenser. It non-linearly increases the efficiency of the condenser.

Changes in losses in the heating network depending on outdoor temperature are shown in Fig. 3.

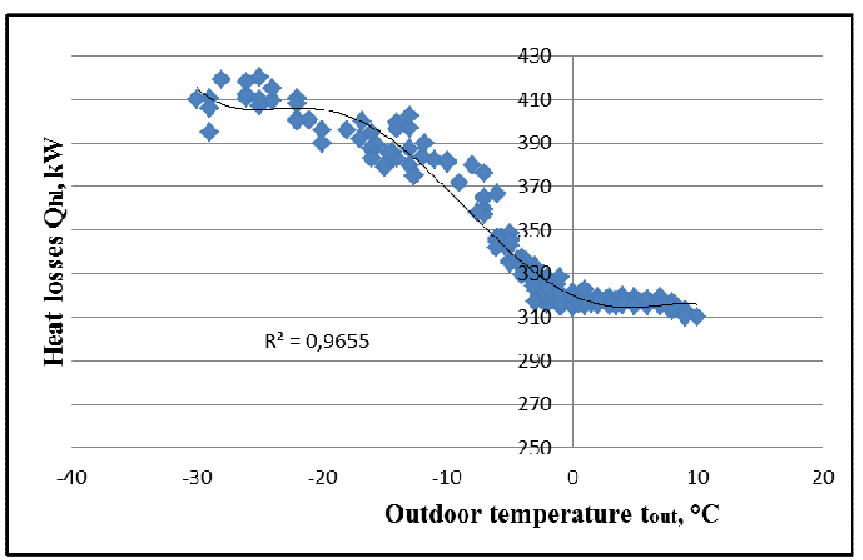

Fig. 3. Changes in losses in heating network depending on outdoor temperature.
The resulting correlation for changes is:

$$
\mathrm{Q}_{\mathrm{hl}}=-2 \mathrm{E}-05 \cdot \mathrm{t}_{\text {out }}{ }^{5}-0,0009 \cdot \mathrm{t}_{\text {out }}{ }^{4}+0,0018 \cdot \mathrm{t}_{\text {out }}{ }^{3}+0,3173 \cdot \mathrm{t}_{\text {out }}{ }^{2}-
$$

When the outdoor temperature increases, the temperatures of the supply and return water decreases; as a result heat losses in the network reduces non-linearly.

Changes in boiler capacity are shown in Fig. 4 .

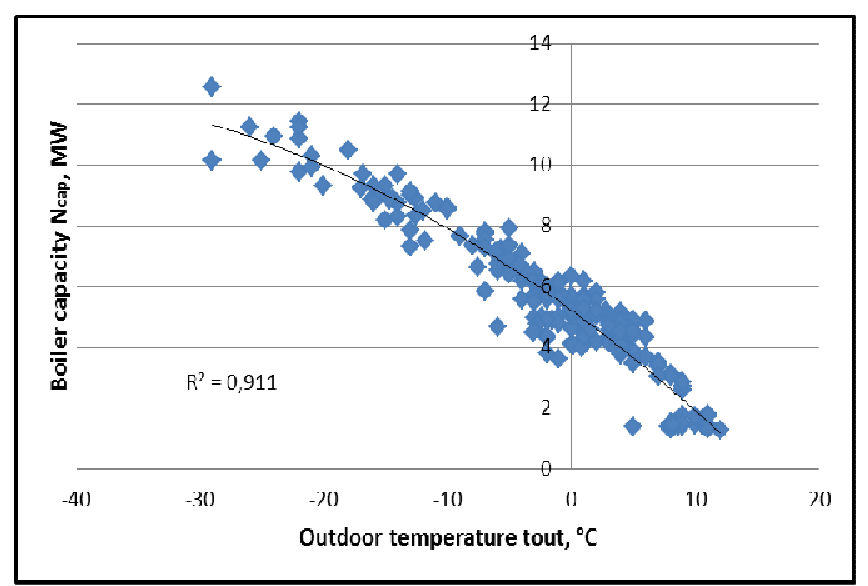

Fig. 4. Changes in boiler capacity depending on outdoor temperature.

The changes are determined by the following expression:

$$
\mathrm{N}_{\text {cap }}=-0.003 . \mathrm{t}_{\text {out }}^{2}-0.299 . \mathrm{t}_{\text {out }}+5.214
$$

When the outdoor temperature lowers, consumer heat load increases. To cover it, a bigger capacity of the boiler is necessary.

\section{RESUlTS}

The empirical correlations (10), (11), and (12) with the expression (9) have been used to calculate the changes in the system's efficiency as the outdoor temperature changes. The resulting data are shown in Fig. 5. A correlation analysis of the obtained data results in equations that characterise the efficiency of the system depending on whether or not a flue gas condenser has been installed in the boiler house. The energy efficiency of a heating system with a flue gas condenser after the boiler is characterised by the following equation:

$$
\eta_{\text {sis }}=-5 \mathrm{E}-07 \mathrm{t}_{\text {out }}{ }^{4}-2 \mathrm{E}-05 \mathrm{t}_{\text {out }}{ }^{3}-2 \mathrm{E}-04 \mathrm{t}_{\text {out }}{ }^{2}+0.003 \mathrm{t}_{\text {out }}+0.892
$$

It is assumed that the efficiency of the boiler is constant and equal to $80 \%$. For comparison, the figure also shows the change in a system's efficiency if a flue gas condenser has not been installed or is not working. In such a case, changes in the system's efficiency are determined by the following equation: 


$$
\begin{aligned}
& \eta_{\text {sis }}=-3 \mathrm{E}-07 \mathrm{t}_{\text {out }}{ }^{4}-1 \mathrm{E}-05 \mathrm{t}_{\text {out }}{ }^{3}-2 \mathrm{E}-04 \mathrm{t}_{\text {out }}{ }^{2}-0,002 \mathrm{t}_{\text {out }}+ \\
& 0,753
\end{aligned}
$$

By entering $\mathrm{K}_{\mathrm{ef}}=0$, expression (9) may also be used to calculate changes in the system's efficiency.

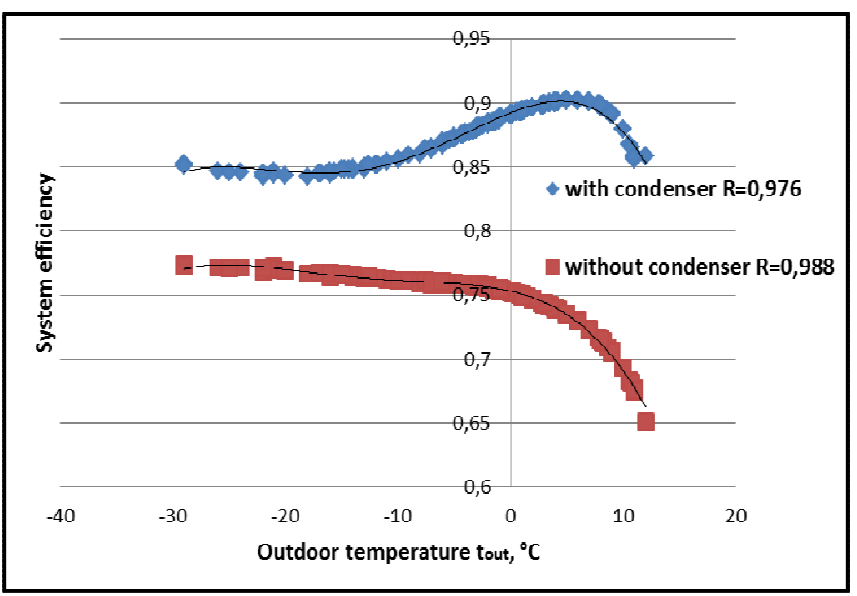

Fig. 5. Changes in heating system efficiency depending on outdoor temperature.

As seen from the obtained results, the efficiency of the system depends on the outdoor temperature, and this dependence is described by a fifth degree polynomial equation. Two extremes are observed:

If deep cooling of the flue gases with vapour condensation takes place in the boiler house, the heating system reaches its maximum efficiency when the outdoor temperature is above $2^{\circ} \mathrm{C}$. As the equation (9) shows, the efficiency of the system is determined by the efficiency of the condenser $\mathrm{K}_{\mathrm{ef}}$, which is the relation of the capacity of the condenser to the capacity of the boiler $\mathrm{N}_{\text {con }} / \mathrm{N}_{\text {cap }}$, and the relation of the heat losses in the network to the capacity of the boiler $\mathrm{Q}_{\mathrm{h}} / \mathrm{N}_{\text {cap }}$. The values are reversely directed. Until the outdoor temperature of $2{ }^{0} \mathrm{C}$, the changes in $\mathrm{K}_{\mathrm{ef}}$ are determining, and the efficiency of the system increases. When the temperature increases exceeding 2 ${ }^{0} \mathrm{C}$, changes in the relation $\mathrm{Q}_{\mathrm{h} /} / \mathrm{N}_{\text {cap }}$ are more rapid.

When the outdoor temperature is very low, the efficiency of the heating system is also low, and efficiency reaches its minimum value when the outdoor temperature is $-25^{\circ} \mathrm{C}$.

Both situations can be explained by the vaporisation and condensation processes that take place in the condenser and stimulate further study of this system in order to increase the efficiency of the system over the entire course of its operations.

In situations without a condenser, the changes in the efficiency of the system are smooth and without extremes. Indicator values decrease as the outdoor temperature increases and are lower than for a system with a condenser.

\section{CONCLUSIONS}

1. The study involves an authorised method for the evaluation of the efficiency of a heating system that is based on the empirical equations obtained as the result of a correlation analysis of the experimental data of the system, which determine changes in the variable parameters of the system.

2. The efficiency of a heating system using a flue gas condenser is higher than that of a system without a condenser. The extremes observed in changes in efficiency depending on outdoor temperature are associated with the specific character of condenser operations.

3. Based on experimental data from the boiler and condenser in 2012-2013, a more in-depth study of the vaporisation and condensation processes within the flue gas condenser is being conducted in order to increase the efficiency of the system over the entire course of its operation.

\section{REFERENCES}

[1] Yan Li a,b, Lin Fu a, Shigang Zhang a, Xiling Zhao "A new type of district heating system based on distributed absorption heat pumps," Energy, Department of Building Environment and Equipment Engineering, Yanshan University, Qinhuangdao, PR China, 36, 2011, 4570-4576.

[2] Chungen Yin, Lasse A,. Rosendahl, Søren K. Kær, "Grate - firing of biomass for heat and power production," Progress in Energy and Combustion Science, Institute of Energy Technology, Aalborg University, DK-9220 Aalborg East, Denmark 34, 2008, pp. 725-754.

[3] A.A. Khana, W. de Jonga, P.J. Jansensb, H. Spliethoff, "Biomass combustion in fluidized bed boilers: Potential problems and remedies," Fuel processing technology, Leeghwaterstraat 44, NL-2628 CA, Delft, Netherlands, 90, 2009, pp $21-50$.

[4] Difs Kristina, Bennstam Marcus, "Energy conservation measures in buildings heated by district heating A local energy system perspective." Energy, Tekniska Verken Linköping AB, Box, 1500, SE-581, 15. Linköping, Sweden 2010, pp. 3194-3203.

[5] Karl Sperling, Bernd Moller, "End-use energy savings and district heating expansion in a local renewable energy system - A short-term perspective," Applied Energy, Department of Development and Planning, Aalborg University, Fibigerstræde 13, DK 9220 Aalborg, Denmark, 92, 2012, pp. 831-842.

[6] Mendonca M, Lacey S, Hvelplund F. "Stability, participation and transparency in renewable energy policy," Policy and Society, Denmark and the United States, 2009, pp. 379-398.

[7] Lund H, Mathiesen BV, "Energy system analysis of 100 p.r cent renewable energy systems: the case of Denmark year 2030 and 2050," Dubrovnik conference on sustainable development of energy, water and environment systems. Dubrovnik, Croatia. Dubrovnik, Croatia; 2007.

[8] Kwangkook Jeong, Michael J. Kessen, Harun Bilirgen, Edward K. Levy, "Analytical modeling of water condensation in condensing heat exchanger," International Journal of Heat and Mass Transfer, 53, 2010, pp. $2361-2368$.

[9] Dalla Rosa A, Li H, Svendsen S. "Method for optimal design of pipes for lowenergy district heating, with focus on heat losses," Department of Civil Engineering, Technical University of Denmark, Brovej, Building 118, 2800 Kgs. Lyngby, Denmark, Energy 36, 2011, pp. 2407-2418.

[10] Vasek L., Dolinay V. "Simulation of heat distribution systems" Recent Researches in Automatic Control, Systems Science and Communications, Faculty of Applied Informatics, Tomas Bata University in Zlin, nam. T.G.Masaryka 5555, 76001 Zlin, Czech Republic, 30, 2012, pp. 190 - 193.

\section{Creative Commons Attribution License 4.0 (Attribution 4.0 International, CC BY 4.0)}

This article is published under the terms of the Creative Commons Attribution License 4.0 https://creativecommons.org/licenses/by/4.0/deed.en US 